\title{
From Net surfers to Net seekers: the www, critical literacies and learning outcomes
}

\author{
ROSS J. TODD \\ Head, Department of Information Studies, University of \\ Technology, Sydney, P.O. Box 123, Broadway, NSW, Australia, \\ 2007,email: Ross.Todd@uts.edu.au
}

\begin{abstract}
This paper provides a conceptual discussion of the critical and information literacies that underpin the effective integration of intemet based information into leaming. The analysis and documentation of a case study of classioom use of the internet during a class research assignment is provided to highlight the importance of developing these critical literacies. The paper recognizes the substantial contribution of Celeste McNicholas, Director of Information Senvices at Marist Sisters' College, Woolwich, Sydney where the case study was undertaken.
\end{abstract}

\section{Background}

Underpinning this paper is the view that schooling is all about providing the best learning opportunities for young people to make the most of their lives as self-directed, self-determining and creative individuals. Schooling in essence is opening doors to the future, albeit an uncertain future. However, one thing is certain. Schooling, as it approaches the millennium, is undergoing a major transformation. Peter Drucker, leading policy and social analyst claims that:

"Every few hundred years in Western history there occurs a sharp transformation. ... Within a few short decades, society rearranges itself - its worldview; its basic values; its social and political structures; its arts; its key institutions. ... We are currently living through such a transformation" (Drucker, 1993: 1).

This transformation, with the learner at the centre, is characterised by the convergence of an information rich society, the rapid growth of information technology, and the emergence of learning themes which focus on the learner. Such themes include lifelong learning, independent learning, contextualized learning, customised learning, flexible learning, transformative learning, collaborative learning, situated learning, and just-in-time learning. Information technology is posited as being a key instrument in enabling these learning to take place. Yet the gaps between the rhetoric and the reality, the enablings and the outcomes, are substantial. Caldwell (1996) claims that schools have not only failed to keep pace with technological change, but also with "reengineering" the learning frameworks in the school in the wake of this technological change and in the wake of

Education for All: Culture, Reading and Information, IASL, 1998 
emerging education themes. He highlights this through the voices of Gerstner et al. (1994) and Dixon (1994):

"Despite the invention of a staggering array of new information tools ... schools transmit information as they have since Gutenberg. ... There is, to be sure, in some schools the promise of a higher technology; a faint sense that things can and should be different. But this is the exception rather than the norm." ... "Worldwide, school is a puffer belly locomotive chugging incongruously through a high-tech landscape."

At the heart of the problem is the fact that such reforms stop at the classroom door. The rhetoric of transforming learning through information technology is easy to present; the implementation of the rhetoric is much more difficult, for it is a complex, time-consuming, challenging, and often a confronting process. The critical issue centers on the integration of information technology into teaching and learning in ways that provide qualitatively different learning experiences, and positive learning outcomes. Alexander and Blight (1996) argue that :

"The promised revolutions in education will only be realized when qualitatively different learning experiences are afforded through the application of information and communication technologies, rather than the provision of 're-packaged' learning experiences which have only the appearance of being 'up-to-date" (Alexander \& Blight, 1966: 2).

This is the key challenge of school education for the millennium. After all, one might argue, if information technology does not foster qualitatively different learning experiences and enhanced learning outcomes, then why invest such costly technology infrastructures in schools. It is a difficult challenge that demands a rethinking of our traditional pedagogy. As Spender (1995) asserts:

"We are the last generation to be reared within a culture in which print is the primary information medium. Because we have grown up and become skilled in a print based community, we have developed certain ways of making sense of the world. We are, to some extent, what print has made us. And now we have to change" (Spender, 1995, p.xv)

There is a growing amount of research evidence to suggest that the integration of information technology into learning can empower learners. A report by Gregoire, Bracewell \& Laferriere (1996), available at the web site: http: $/ /$ www.tact.fse.ulaval.ca/fr/html/impactnt.htm/ provides a substantial review of research which demonstrates that:

- new information technologies have the power to stimulate the development of intellectual skills such as reasoning and problem solving, learning how to learn, and creativity.

- new information technologies can contribute in several ways to better learning in various subjects and to the development of skills and attitudes. The nature and breadth of learning depend on previously acquired knowledge, and on the type of learning activity. 
- most students show greater spontaneous interest in a learning activity that uses a new technology than in the traditional approaches in class.

- the attention span or concentration that the majority of students are willing to devote to learning activities is greater when they use a new information technology than when they are in a traditional setting using traditional resources.

- new technologies have the power to stimulate the search for more extensive information on a subject, and a more satisfying solution to a problem.

- the use of new technologies promotes co-operation among students in the same class and among students or classes in different schools.

- if the new technologies are used in such a way as to exploit their potential, the teacher interacts with students much more than in a traditional classroom, as a facilitator, a mentor, a guide to the discovery and gradual mastery of knowledge, skills and attitudes.

- teachers begin to view knowledge less and less as a series of facts to be transferred and more and more as a process of continuous research in which they share the difficulties and results with their students.

- successful implementations of computer-based learning technologies are associated with trained and knowledgeable teachers in the classroom.

While these are exciting findings, the outcomes do not happen by chance. They do not happen by simply placing a student in front of a computer and hoping that something miraculous will take place at the screen, and that effective and meaningful learning will take place. It is increasingly clear that information technology of itself does not directly change teaching and learning, nor improve learning outcomes. Rather, the essential element is how technology is incorporated into day-by-day teaching and learning. The fundamental thinking, rethinking, design and redesign of learning and teaching practices in response to electronic information technology is yet to happen.

\section{Key challenge: developing critical literacies}

In essence, the key challenge confronting schooling in the wake of the information technology revolution and the enormous volume of information it provides is empowering learners to be creative, critical and constructive users of information. This has to be the central feature of any pedagogical transformation involving information technology. And central to this is developing students' critical literacies: developing the skills needed so that students are able to look critically at information and to question and challenge the words of ideas on the Net; are able to understand and analyze the ways information works to empower some and exclude others; and have the capability of managing and effectively 
utilizing the quantities of information they confront. Kehoe (1993) sums up the essential dilemma:

"Access to vast amounts of information is not the whole answer. The power to discover the right information quickly and easily, to separate nice to know from need to know information is essential if superhighway users do not drown in electronic junk information. ... An information flood does not necessarily mean that people become informed" (Kehoe, 1993).

The development of critical literacies embrace 3 essential dimensions. These dimensions connecting, interacting, utilizing - are active thinking and reasoning processes and embed an information literacy framework that teacher-librarians have championed for many years now. These dimensions will only be realized in the classroom when explicit and systematic learning activities are designed and implemented on a daily basis in all curriculum areas. These activities need to center on the following processes:

CONNECTING with the world of information:

questioning, defining, searching, locating, finding

INTERACTING with the world of information:

questioning, challenging, evaluating, filtering, analyzing, organizing, interpreting, understanding, synthesizing, critiquing, constructing, reflecting

UTILIZING the world of information:

applying, finding help, getting direction, moving on, solving needs, making decisions, developing applications, implementing actions, constructing solutions.

The importance of developing these literacies-when one considers the undifferentiated and ambiguous world of the Net - is a matter of some urgency. Burbules (1997) describes the Net as an indiscriminate mix of five types of information, where the quality, importance and reliability of information is difficult to determine. These types are:

INFORMATION: factual; clearly sourced; bears all the traditional hallmarks of reliability and quality.

MISINFORMATION: information judged to be false, out of date, or incomplete in a misleading way.

MALINFORMATION: potentially dangerous or damaging information; inappropriate information; information people feel uncomfortable with in openly accessible circulation.

MESSED UP INFORMATION: poorly organized and presented information; sloppy design; problematic navigation.

USELESS INFORMATION: (recognizing one person's trash is another person's treasure) information that appears to serve little informing purpose.

In the ambiguous world of Net information, the development of critical literacies is fundamental to assisting learners in making decisions about: what to believe, what to doubt, what to pay attention to, and what to care about. At a more specific level, these 
literacies enable students to make evaluations of web sites; to ask important decisions such as:

- what is this site trying to do?

- what is this site trying to do to me?

- whose interests are being served here?

- what is the text trying to say?

- what are the possible meanings?

- what do 1 already know and how does this relate to it?

- how does this relate to other sites? other sources?

- what are the alternative / opposing views?

- where can I find out about alternatives?

- how does this site help me construct an alternative position?

- what do I do with this site now?

- who can I talk to about this site?

- which voices are silent here?

- what actions can / should / will I take?

These are important questions that have always underpinned the use of information resources. However, access to the World Wide Web and its vast store of information creates a different learning context. Key differences to traditional learning contexts include:

- the seductiveness of the technology and the captivating media hype shaping an expectation that every answer is on the Net and is an effortless button click away;

- the complexity of information organization and linkages, where a traditional linear flow of information is replaced by a hyperlinked structure enabling multiple pathways of navigation; poorly organized and often with limited advance organizers;

- the integration of different media - sound, text, video, animation, graphics and the potential of noise / overload that this can present. This is particularly 
the case where much of the integration of different media is no more than bells and whistles to show designer's flair;

- indicators of credibility found in traditional sources in school libraries are often not present in Net information. Common features of the Net include: the invisibility of web authors; the problem of unknown authorship; origins of information less direct; assertions sourced in other unreliable sources; and indiscriminate inclusion of material;

- everything on the Net looks authentic as an official publication. There is plausible presentation of false/misleading information-such that the boundaries between rumor, gossip, and what is credible and authentic, are blurred;

- information on the Net often stands without a functional context. In many sites, information just sits there, without any background or contextual statements, or without any links to other sites which may help place it in a meaningful context.

\section{The Net and learning dilemmas: a case study}

Do students effectively use the Net? How can their interaction with the Net be made more meaningful and productive? The case study summarized here sought to examine how students made use Net information in the process of their learning. It sought to identify learning barriers and difficulties and to develop and implement information literacy/critical literacy centered teaching and learning strategies to address these concerns. The case study took place at Marist Sisters' College, Woolwich (Sydney) under the leadership of Celeste McNicholas.

The study involved one classroom teacher and two senior classes, one geography and one religious education class involving a total 42 students. The research tasks were set by the classroom teacher and designed without consultation with the teacher librarian this serving to represent the more common practice rather than a task designed to suit the Internet aspect of the work.

Each class comprised two randomly selected groups. Group A used information sources considered traditional by Marist Sisters' College, that is print texts, multimedia and electronic indexes and full text services. Group B accessed the Internet, primarily the World Wide Web, from any of fifty possible sites around the College using Netscape as a search engine and unconstrained by any electronic censorship. Group B students had open access to the Net at all times throughout the course of the study. The tasks were initially set with a firm time line that reflected the program for both subjects. The research was planned using naturalistic observation of the students and teacher, recording their experiences and impressions of 'traditional' versus new information sources while documenting the process and the product outcome.

Prior to beginning their tasks both groups of students were asked to record their search plans making comment on what information was to be to looked for and where they 
expected to find it. In addition a process diary was used by each student to make comment about their impressions and perceptions of the sites visited and judgments about the quality and usefulness of the information gathered.

The learning process was tracked in depth from the time the students were given the research tasks, to the time the tasks were assessed by the classroom teacher. An action research framework underpinned the process. This involved five phases of identify, plan, act, observe, and reflect. The process involved careful observations of and discussions with the students during their work; it involved articulating problems, barriers, concerns; then planning and implementing appropriate teaching and learning strategies based on an information literacy framework to address the concerns; and to evaluate and reflect on the processes with a view to ongoing planning, classroom action, and evaluation.

The outcomes of this study are presented in the following table.

\begin{tabular}{|c|c|c|}
\hline LEARNING DILEMMAS & $\begin{array}{l}\text { INFORMATION } \\
\text { LITERACY-BASED } \\
\text { REQUIREMENTS } \\
\text { TEACHING AND } \\
\text { LEARNING } \\
\text { STRATEGIES }\end{array}$ & EMERGING ISSUES \\
\hline $\begin{array}{l}\text { superficial analysis / diagnosis } \\
\text { of the learning task } \\
\text { inability to construct } \\
\text { appropriate and } \\
\text { effective search } \\
\text { strategies }\end{array}$ & $\begin{array}{l}\text { defining information } \\
\text { brainstorming and concept } \\
\text { mapping of key ideas of task } \\
\text { activities to identify } \\
\text { narrower, broader, } \\
\text { related and alternative search } \\
\text { terms }\end{array}$ & $\begin{array}{l}\text { tasks need to be designed with } \\
\text { an understanding of } \\
\text { metacognitive processes } \\
\text { colloquial English is not Net } \\
\text { English } \\
\text { perceptions of a topic's } \\
\text { 'aboutness' were too narrow / } \\
\text { fuzzy }\end{array}$ \\
\hline $\begin{array}{l}\text { not a clear understanding of } \\
\text { search engines } \\
\text { using only one search engine } \\
\text { expectation that answer will } \\
\text { be provided - a one-stop shop } \\
\text { for information }\end{array}$ & $\begin{array}{l}\text { locating } \\
\text { information } \\
\text { explore help screens for each } \\
\text { search engine and analyze } \\
\text { differences in constructing } \\
\text { search designs } \\
\text { test search designs on different } \\
\text { engines and compare outputs } \\
\text { guided search activities } \\
\text { one-to-one assistance }\end{array}$ & $\begin{array}{l}\text { sloppy searches are expensive, } \\
\text { both in terms of learner time } \\
\text { and effort, and on-line cost } \\
\text { extreme frustration of poorly } \\
\text { designed approaches to } \\
\text { searching negates positive } \\
\text { aspects of the Net } \\
\text { perceptions of what the Net is } \\
\text { impede the use / exacerbate } \\
\text { frustrations }\end{array}$ \\
\hline
\end{tabular}




\begin{tabular}{|c|c|c|}
\hline $\begin{array}{l}\text { real difficulty in judging the } \\
\text { quality of the information } \\
\text { found at the various web sites } \\
\text { not a clear understanding of } \\
\text { selection criteria }\end{array}$ & $\begin{array}{l}\text { selecting } \\
\text { information } \\
\text { understanding the range of } \\
\text { on-screen cues to assist quality } \\
\text { of judgment } \\
\text { structured activities to } \\
\text { compare sources } \\
\text { organized sharing to } \\
\text { collaborate on site searches }\end{array}$ & $\begin{array}{l}\text { students need to confront and } \\
\text { learn to deal with the diversity } \\
\text { of the Net } \\
\text { is the pre-selection and } \\
\text { provision of a limited number } \\
\text { of "good sites" realistic or legal? } \\
\text { who determines what is a "goo } \\
\text { site"? }\end{array}$ \\
\hline $\begin{array}{l}\text { copying large slabs of } \\
\text { information seen as legitimate }\end{array}$ & $\begin{array}{l}\text { organizing information } \\
\text { activities to foster skills of } \\
\text { sorting ideas } \\
\text { comparing and contrasting } \\
\text { different sites for the same } \\
\text { content } \\
\text { comparing web site } \\
\text { information with resources in } \\
\text { the library } \\
\text { synthesis activities } \\
\text { understanding how to } \\
\text { construct an argument using } \\
\text { ideas from different sources } \\
\text { developing note-taking skills } \\
\text { eg concept mapping }\end{array}$ & $\begin{array}{l}\text { time management is a critical } \\
\text { factor } \\
\text { required skills can not be } \\
\text { assumed } \\
\text { tasks that encourage } \\
\text { regurgitation receive } \\
\text { regurgitation } \\
\text { prioritize the probable success } \\
\text { rate of any source to a given } \\
\text { task }\end{array}$ \\
\hline $\begin{array}{l}\text { indiscriminate dumping to } \\
\text { print } \\
\text { cut and paste was seen as the } \\
\text { solution } \\
\text { group collaboration led to } \\
\text { identical presentation }\end{array}$ & $\begin{array}{l}\text { presenting } \\
\text { information } \\
\text { using different forms of } \\
\text { information } \\
\text { presenting information in } \\
\text { different forms. }\end{array}$ & $\begin{array}{l}\text { imposed formats restrict } \\
\text { responses } \\
\text { self-imposed barriers limit } \\
\text { productivity } \\
\text { visual literacy is understressed }\end{array}$ \\
\hline $\begin{array}{l}\text { students have no role in the } \\
\text { process of evaluation } \\
\text { time frustrations meant little } \\
\text { reflection on process or output }\end{array}$ & $\begin{array}{l}\text { assessing } \\
\text { output } \\
\text { review and comment on } \\
\text { completed product } \\
\text { redesign the task }\end{array}$ & $\begin{array}{l}\text { mechanisms for feedback on } \\
\text { process and product are } \\
\text { necessary }\end{array}$ \\
\hline
\end{tabular}

(Todd \& McNicholas, 1997: 370-371)

Based on these findings, six key learning dilemmas were conceptualized from this case study. They were derived from our observations, and stated in students' comments. Typical comments included:

"I don't know what to search for" 
"I'm lost"

"I know there's information in here but I can't seem to find it"

"I can't work out if the info's good or not"

"I can't find any useful information"

"I get so much useless information"

"The Internet's great-a one stop shop for information"

"it doesn't encourage you to use your brain"

"it's so easy to cut and paste"

In summary, the six learning dilemmas were:

DESIGN OF RESEARCH TASKS: A major barrier to effective searching was a poorly designed research task. This is a problem that teachers must resolve. This problem compounds the difficulties as student engage in the search, analysis and synthesis processes.

UNDERSTANDING SEARCH ENGINES: This was a major problem. Search engines work differently, and their scope, capabilities, and search and logic processes need to be understood in order to generate a search output that is precise, relevant and with a minimum of "noise" or junk information.

SEARCH DESIGN: Coupled with poorly designed research tasks, weakly developed skills to analyze this task for searchable key words, based on an understanding that Net English is often not classroom English, were clearly evident. Lateral thinking skills to establish narrower, broader, and related terms were not strongly evident. The problem was compounded by the inability of students to construct a search string based on the principles of Boolean logic that underpins the Net search engines.

INFORMATION QUALITY: Judging the quality and utility of information for the required task was a major barrier for students. They have traditionally worked in a school environment where library resources are assumed to be "good" by their mere presence in the collection. The assumption that all information is "good" has been carried over to the Net.

CONSTRUCTION OF INFORMATION: Abilities to analyze and synthesize information, and to construct a personal answer that demonstrated understanding of the ideas, were poorly developed. There was a tendency to scroll through pages to find the answer, and to cut and past the relevant paragraph into a document that was to become the research assignment.

PRODUCTIVITY: Poorly developed search skills, and consequently the huge volumes of information to sift through, resulted in a prolonged and frustrating search process. This impacted both on students' productivity as well as on time-cost efficiencies of being online on the Net. 


\section{Conclusions}

The Internet has already changed us. It is immediate, and pervasive, it surrounds us with information - it puts a world of information at our fingertips. Underpinning the Internet in a learning context is the assumption that this connectivity is forging learning communities between students, teachers, schools and professionals on a global scale, and is of benefit to learners. The rapid growth of on line electronic information services in schools inevitably raises the question of its impact on learning: on the learning process, on the learning environment, and learning benefits for students. Is it really worth the investment? The learning dilemmas emerging from the study range from competency levels with search engines and syntax, through to concepts of search design and task construction. They warrant further examination. Clearly the dilemma faced by learners when moving from the safe ground of a preselected paper based information collection to the randomness of the information collection that is the Internet, is one which needs to be addressed through the methodical identification and acquisition of appropriate critical literacies and skills.

It is important that teacher-librarians play a key transformational leadership role in order to effect change in schools, and to help students become effective Net seekers, rather than surfing the surface of the information flood. At a broader level, the study highlights four things we have to do if the Internet is to be a useful learning tool for students, and teacher-librarians can contribute significantly to this:

Domesticate it: make it part of our ordinary experience. To do this, we need the intellectual tools to be able to effectively use it. These intellectual tools are the skills that underpin information and critical literacies.

Integrate it: we have to take time to answer the hard questions; reflect on our own teaching methodologies to ensure we are using it to provide the best learning opportunities for students. Effective integration is underpinned by rethinking and redesigning some of our traditional pedagogical practices.

Scale it: we have to see the Net in its real world context. It is just one more potential source of information. It is not the only source, and its effective use is in the context of one of many sources of information that can be used.

prove it: is the Net really adding value? Is it really worth the investment? There is an urgent need to provide evidence that the Net is empowering learners and providing qualitatively different and positive learning outcomes.

\section{References}

Burbules, N. (1997). Struggling with the Internet. Campus Review, August 13-19, 19-20, 22.

Caldwell, B. (1996). Redesigning schooling for the information age: the role of networking. Keynote address at conference Electronic Networking and Australasia's Schools, ITEC, Sydney, April 12, 1996.

Dixon, R. (1994). Future schools: how to get there from here. Phi Delta Kappan. 75(5), 360-365.

Drucker, P. (1993). Post-capitalist society. New York: Harper Business. 
Gerstner, L., Semerad, R., Doyle, D., \& Johnston, W. (1994). Reinventing education. New York: Dutton.

Gregoire, R., Bracewell, R. \& Laferriere. T. (1996). The contribution of new technologies to learning and teaching in elementary and secondary schools - documentary review. Collaboration of Laval University and McGill University. Web Site: http://www.tact.fse.ulaval.ca/fr/html/impactnt.html

Kehoe, L. (1993). Casting the net worldwide. Financial Times, 30 November, 11.

McNicholas, C. \& Todd, R. (1996) New kids on the box: is it worth the Investment. Scan $15(4), 40-42$.

Spender, D. (1995). Nattering on the Net. Melbourne: Spinifex.

Todd, R. (1996) Independent learning and information literacy: an essential partnership for learning. In Maureen Nimon (Ed), Learning resourcefully: challenges for teacher librarians in the information age (Library Challenges Series Number Nine, pp 3-18). Adelaide: Auslib Press.

Todd, R. \& McNicholas, C. (1997) Electronic information and learning organisations" In Information online \& on disc 97: Proceedings of the Eighth Australasian Information online \& on disc conference and exhibition, Sydney Convention and Exhibition Centre, Sydney Australia. 21-23 January 1997 (pp. 363-373). Sydney: Information Science Section, Australian Library and Information Association. 